\title{
EL VALOR DE LA FELICIDAD
}

\section{The Value of Happiness}

Rosse Mary Ríos Chávez*

\begin{abstract}
Resumen
La felicidad es un valor que todas las personas quieren alcanzar, la felicidad puede variar según el momento. Puede ser fugaz, dependiendo de qué perspectiva se vea. En el presente ensayo se va a dar desde un punto vista personal, en el cual se plantea que la felicidad es algo subjetivo ya que la felicidad y la satisfacción personal están relacionados de manera muy cercana.
\end{abstract}

Palabras clave: Felicidad, valor, persona, satisfacción.

\begin{abstract}
Happiness is a value that all people want to achieve. Happiness can vary depending on the moment or it can be fleeting, depending on which perspective you see. In the present essay it will be given from a personal point of view, in which it is stated that happiness is something subjective since happiness and personal satisfaction are related very closely.
\end{abstract}

Keywords: Happiness, value, person, satisfaction

* Maestranda en Psicología con mención en Psicología Clínica y de la Salud por la Universidad Femenina del Sagrado Corazón. Docente de la Escuela de Oficiales de la Fuerza Aérea del Perú. rosse.rios@gmail.com, Lima - Perú. Orcid: 0000-0002-3873-8356

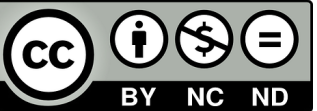

Para utilizar este artículo debe incluir: Autor / Título / ISSN. 
Algún día en cualquier parte, en cualquier lugar indefectiblemente te encontrarás a ti mismo, y ésa, sólo ésa, puede ser la más feliz o la más amarga de tus horas

Pablo Neruda

\section{INTRODUCCIÓN}

Para la Real Académica Española, la felicidad es definida como "estado de grata satisfacción espiritual y física" (Real Academia Española, s.f., definición 1).

Tomando en cuenta el sentido etimológico de la palabra "felicidad" significa suerte favorable, suceder por casualidad, tener buen éxito. Siendo definida por Lalande (1953) como un "estado de satisfacción completa, que llena toda conciencia ... satisfacción de todas nuestras inclinaciones, tanto en intensidad, grado y duración" (pp. 464-465).

Para Heylighen (1992) la felicidad puede ser de dos maneras; una la felicidad pasajera, por ser una sensación grata que puede venir de una vivencia propia de bienestar y la felicidad duradera, que es el predominio una sensación grata que se da por un tiempo prolongado.

Según Argyle (1992) la satisfacción es un factor primordial de la felicidad, viviendo la satisfacción de lo bien que pueden ir o han ido las cosas.

Alarcón (2006) la felicidad significa una situación de satisfacción que experimenta cada persona de disfrute cuando tiene un bien deseado.

Teniendo como referencias algunas definiciones de la felicidad, se podría decir que el valor de la felicidad es algo relativo a cada persona, es importante también tener en cuenta que el concepto de felicidad y el valor que se le da ha atravesado diferentes etapas según el pasar de los tiempos.

Lo que producía felicidad en épocas pasadas no es ni remotamente el concepto que se tiene hoy por hoy, por ende, el valor que se le asigna ha variado significativamente, si bien los principios básicos como cooperación, ganas de hacer lo correcto, servir a los demás, amabilidad entre otras características positivas siguen fuertemente asociados a ésta.
Pongamos un claro ejemplo de esto: Durante muchos siglos y hasta hace relativamente poco, (hablamos de la década de los 50,60) el valor que una mujer daba a su felicidad se manifestaba en que tan buena madre y esposa llegaba a ser. Mientras más fecunda, más dedicada a los quehaceres del hogar y al cuidado del marido, mejor vista era en la sociedad y eso le producía una gran complacencia, era feliz de ese modo. Actualmente ha habido cambios diametrales en la valoración que dan ahora a la felicidad. Ahora se trata de su realización personal, profesional, de procurarse cuidados para ella, existiendo un marcado componente hedonista.

Este último medio siglo conocido como la "era digital" en cual todavía no hay mucha información de cómo impacta esta nueva tecnología en la valoración de la "felicidad", Ibañez (2018) en su artículo "La era digital y la felicidad" expone algunos puntos muy interesantes al respecto en donde analiza si esta tecnología hace a las personas más felices o no, refiriendo lo siguiente "La tecnología ha ido cambiando el estilo de vida de cada ser humano, desde el trabajo, hasta la forma de interacción con los demás. Lo importante es que las herramientas están hechas para ser bien utilizadas, de esta forma la gente puede ser más feliz y no lo contrario. Existen varios miedos que hacen que a la gente le genere ansiedad y no sea feliz, uno de ellos es que piensa que entre más tecnología exista menos puestos de trabajo van a haber, y que las máquinas remplazarán al hombre.... El segundo miedo es en cuanto a la interacción con los demás ... pero somos los únicos que podemos adiestrarnos en cómo es la mejor forma de interactuar con ella, porque nunca una máquina remplazará el calor humano de las personas, y somos nosotros los que debemos trabajar en las relaciones interpersonales" para esta autora la tecnología puede traer la felicidad, pero está en cada persona como utilizarla y hacer que le traigo satisfacción, siendo esta opinión en cierta parte subjetiva porque cada persona va tener una percepción distinta y subjetiva sobre la tecnología y la felicidad.

Este siglo ha sido pródigo en cambios de los estilos de vida establecidos. También ha habido profundos cambios de pensamiento en cómo debe ser la composición de una familia y su rol en la sociedad. Existen familias monoparentales, familias con ambos padres del mismo sexo, y demás formas familiares que 
actualmente son vistas con naturalidad. Antes, ser hijo de una madre soltera o ser huérfano de padre o madre producía sufrimiento a estos niños y adolescentes, el ser discapacitado o tener poca habilidad para los deportes o la música, etc., era mal visto por algunos sectores de la sociedad, pero ahora en la actualidad esas circunstancias ya no son razón de tristeza y sufrimiento necesariamente.

Hoy con la tecnología muchas de estas personas se han erigido en geeks, con habilidades y destrezas sobresalientes en el área del mundo digital y han capitalizado esto en actividades que les han brindado muchas regalías económicas y considerando que muchas veces se trata de personajes solitarios, sin vida familiar sin amistades, centrados solo en sus computadoras, el valor que le dan a su felicidad es cuestionable desde el punto de vista de nuestro sistema de valores.

El éxito en nuestra sociedad actual ya no está basado en clasificar a la gente según la familia de la que proviene, o según las cualidades físicas que pueda tener, sino en su conocimiento de este nuevo mundo digital, es más, las personas que tienen poco o nulo conocimiento de éste, son consideradas como analfabetas digitales, en este sentido el bien o bienes deseados que producen felicidad son de naturaleza diversa. Son cosas a las que las personas les conceden un valor o una connotación positiva. (Alarcón 2006).

Su bienestar y realización derivan de que tan exitosos económicamente se vean, que tan jóvenes aparentan ser, que tan conocedores de la tecnología son, Es decir, todo lo atribuyen a factores externos.

Este éxito hace que ahora la valoración de la felicidad esté principalmente asociada a la cantidad de dinero que una persona pueda acumular con el mínimo esfuerzo. Casi todo ahora funciona en línea. Cada vez interactuamos menos con nuestras semejantes, privándonos así de un eje importante en el enriquecimiento de nuestro mundo interno como son las relaciones interpersonales.

Aun así, existen corrientes de pensamiento basados en la valoración de la felicidad atribuida a factores internos. que tienen bastante acogida en un gran sector de nuestra sociedad como por ejemplo, la práctica de filosofías de origen oriental como el yoga.
Revisando en diferentes páginas web donde se promocionan las ventajas y beneficios de practicar esta disciplina se encontró mucha información relacionada a la felicidad que se resume de la siguiente manera:

a. El yoga te pone en contacto con tu cuerpo y te enseña a amarlo. Esto te hará feliz.

b. Al practicarlo con regularidad aumentan los niveles de los siguientes neurotransmisores: serotonina oxitocina y GABA. Esto influye en la química de tu cuerpo y te induce a una sensación de bienestar generalizada.

c. Disminuye tu presión arterial y tus niveles de cortisol conocida como la hormona del estrés.

d. Como te enseña a respirar de forma profunda, te ayuda a manejar el estrés

e. Todo lo antes mencionado reduce tu ansiedad y te relaja.

Hay muchas variantes de lo anteriormente señalado en otras culturas pero el fondo es el mismo; es decir, conectarte con tu yo interno y procurarte un estado de bienestar prolongado, lo cual está respaldado por diferentes investigaciones y autores, Veenhoven (2001) refiere que el no ser feliz, puede generar estrés, el cual puede aumentar la posibilidad contraer diferentes enfermedades, en cambio el ser feliz beneficia el crecimiento psicológico proporcionando una mejor capacidad para hacer frente a las cosas.

En este mundo donde todo es tan rápido y a veces no hay tiempo para conectarnos ni desarrollar nuestras relaciones interpersonales y además en donde se da mayor valor a los factores externos, es difícil encontrar el valor de la felicidad.

En la medida que más nos familiaricemos con estilos de vida saludables y demos menos importancia a factores externos y variables como el dinero, la felicidad, el conocimiento de nuevos programas digitales que cada vez nos hacen más dependientes de la tecnología, y que los inculquemos en nuestra comunidad, en nuestros parientes, y allegados, podremos hallar el valor de la felicidad. Para Rojas (2014) el fin de la felicidad es que una persona tenga una realización plena de sí mismo, en donde una actitud lógica y consecuente con los principios que uno sigue, junto con la lealtad son dos herramientas 
necesarias para que una persona pueda alcanzar la felicidad.

Una forma de acercarnos a la felicidad es tomar como filosofía de vida estos puntos de vista:

a. Encontrar la felicidad en lo que hagas.

b. Intensificar tus relaciones interpersonales.

c. Cuidar de tu salud y de tus finanzas.

Para concluir este ensayo quisiera resaltar que uno no puede basar su felicidad sobre la desdicha de otra persona, y es así que coincido con Margot (2007) quien refiere lo siguiente:

... Nuestro destino individual está ligado al de la humanidad entera. La felicidad de unos no puede edificarse sobre la desdicha y la explotación de otros: la justicia social es necesaria. Si mi existencia está siempre amenazada, si siempre tengo hambre o si debo trabajar sin parar para ganar apenas lo que me permite subsistir, si el miedo y la preocupación nunca me abandonan, es obvio que no puedo avanzar en la búsqueda de la felicidad...

\section{REFERENCIAS}

Alarcón, R. (2006). Desarrollo de una Escala Factorial para medir Felicidad. Revista Interamericana de
Psicologia/Interamerican Journal of Psychology, 40(1), 99-106. ISSN: 0034-9690. https://www. redalyc.org/articulo.oa?id=284/28440110

Argyle, M. (1992). Psicología de la felicidad. Alianza Editorial.

Heylighen F. (1992) A cognitive-systemic reconstruction of Maslow's theory of selfactualization. Behavioral Science 37(1), 39-58. https://doi.org/10.1002/bs.3830370105

Ibañez, P. (19 noviembre 2018). La era digital y la felicidad. La República. https://www.larepublica. co/analisis/pilar-ibanez-514336/la-era-digital-yla-felicidad-2794834

Lalande, A (1953). Vocabulario técnico y crítico de la filosofía. (1). El Ateneo.

Margot, Jean-Paul. (2007) La Felicidad. Revista Praxis Filosófica, 25, 55-79, https://doi.org/10.25100/ pfilosofica.v0i25.3112

Real Academia Española. (s.f.). Felicidad. En Diccionario de la lengua española. Recuperado en 11 de mayo de 2019, de https://dle.rae.es/ felicidad? $\mathrm{m}=$ form

Rojas, E. (2014) Una teoria de la felicidad. (36ta). Cie Inversiones Editoriales Dossat

Veenhoven, R. (14-15 enero de 2001). What we know about happiness. Paper presented at the dialogue on "Gross National Happiness", Woudschoten, Zeist, The Netherlands.

Fecha de recepción: 17 de julio 2019

Fecha de aceptación: 27 de agosto 2019 